\title{
Resenha de Ostermann e Meneghel (Orgs.) (2012) Humanização, Gênero, Poder: contribuições dos estudos de fala-em-interação para a atenção à saúde
}

\author{
Daniela Negraes Pinheiro Andrade \\ Universidade do Vale do Rio dos Sinos
}

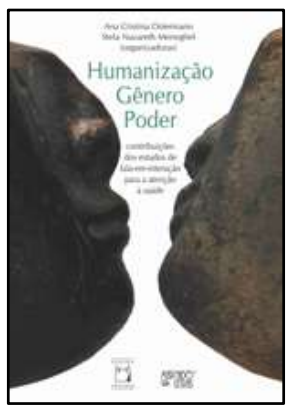

Relações (as)simétricas, (des)humanizadas e (de)generificadas: um mergulho em águas claras

Humanização, Gênero, Poder: contribuições dos estudos de fala-em-interação para a atenção à saúde - Fiocruz e Mercado de Letras (Ostermann e Meneghel, 2012) - merece distinta apreciação por diversas razões. Em primeiro lugar, porque a obra é organizada por uma linguista aplicada, Ana Cristina Ostermann, e uma médica da área da saúde coletiva, Stela Nazareth Meneghel, e possui como colaboradoras, além das próprias organizadoras, pesquisadoras da grande área de Letras e Linguística. A configuração autoral da obra é significativa na medida em que a coletânea apresenta pesquisas focadas na comunicação profissional de saúde - usuário, mais especificamente, interações face a face em contexto
Ostermann, Ana Cristina \& Meneghel, Stela Nazareth (Orgs.) (2012). Humanização, Gênero, Poder: contribuições dos estudos de fala-eminteração para a atenção à saúde. Campinas: Mercado de Letras; Rio de Janeiro: Fiocruz.

ISBN: 978-85-7591-221-8

de consultas de ginecologia e obstetrícia e de psicologia ocorridas em um posto de saúde do Sistema Único de Saúde (SUS) - sistema de saúde público do Brasil. Desse modo, a obra, por seu caráter inter e multidisciplinar, como bem pontuado por Liliana Cabral Bastos, prefaciadora do livro, colabora com o propósito de se "fazer uma Linguística Aplicada aplicável, isto é, assum[e] o compromisso de produzir conhecimento de relevância social" (Oliveira, 2013, p. 145) para e em conjunto com a área da saúde por meio da investigação da fala-em-interação.

O segundo motivo pelo qual a coletânea merece atenção remonta ao arcabouço teóricometodológico utilizado para análise de dados, qual seja, o da Análise da Conversa de base etnometodológica (Sacks, 1992; Schegloff, 2007). A Análise da Conversa (AC), "trata as 
práticas de agir e de fazer sentido na [e por meio da] fala-em-interação como fundamentadas em um conjunto de normas institucionalizadas que são fundamentais para a inteligibilidade da própria ação social" (Heritage, 2004, p. 104). Desse modo, o que está no foco nas análises e discussões apresentadas são as conversas entre os participantes das consultas, gravadas em áudio e minuciosamente transcritas, e não, por exemplo, entrevistas ou questionários aplicados post factum. Desse modo, humanização, gênero e poder são discutidos à luz dos procedimentos tácitos e racionalmente organizados empregados pelos próprios interlocutores de forma a colaborativamente alcançarem uma comunicação significativa e ordenada (Hutchby e Wooffitt, 1998). Conforme explica Liliana Cabral, no prefácio, as autoras apresentam "cuidadosas análises de como acontecem as consultas, de como médicos e pacientes falam sobre tópicos difíceis e delicados como a sexualidade e de como nessas falas se constroem relações de poder" (p. 7)

0 terceiro aspecto elogiável da obra remete ao cuidado que as organizadoras tiveram de inserir, além do capítulo introdutório, um capítulo metodológico. Escrito por Ana Ostermann, uma das pesquisadoras exponenciais da área da $\mathrm{AC}$ de base etnometodológica no Brasil, o capitulo versa sobre princípios basilares da perspectiva teórico-metodológica adotada nos capítulos analíticos. A linguagem direta e objetiva do texto presta enorme serviço aos leitores interessados na metodologia da AC aplicada à comunicação provedor de saúdeusuário. O livro também apresenta um glossário de termos de estudos de fala-eminteração, escrito por Joseane de Souza e Ana Cristina Ostermann. Assim, os leitores são alicerçados com noções conceituais e significados de termos técnicos que facilitam o acompanhamento das análises e discussões oferecidas.

A obra está organizada em cinco partes. Afora a introdução e o capítulo metodológico, que constituem o primeiro segmento, o livro apresenta três partes formadas por capítulos analíticos e uma parte destinada ao fechamento da obra. Uma divisão temática motiva a organização dos capítulos analíticos. Na segunda parte, figuram artigos que tratam sobre como se estabelecem relações de poder nas relações interpessoais no contexto investigado.
$\mathrm{Na}$ terceira parte, incluem-se estudos que versam sobre práticas humanizadoras em saúde exercidas no discurso e observadas nas consultas analisadas. Questões de gênero e sexualidade em interconexão com a linguagem são tratados nos artigos que integram a quarta parte. Por fim, o livro encerra-se com um capítulo em que as organizadoras discorrem sobre como os estudos focados em eventos de fala-em-interação podem contribuir com aspectos relacionados à atenção à saúde.

Poder, tema em foco na segunda parte do livro, na perspectiva bourdieusiana é concebido como categorias de percepção e orientação de condutas naturalizadas e essencializadas por parte dos indivíduos que, ao partilharem e replicarem relações de hierarquia, asseguram a inteligibilidade do mundo social como fundamentado em assimetrias de prestígio e dominância duráveis. Pierre Bourdieu (1991) chama de violência simbólica, ou poder simbólico, as formas de poder exibidas na vida cotidiana, raramente impostas pela força física, mas exercidas tácita e legitimamente por serem reconhecidas pelas partes envolvidas como constitutivas da hierarquia das relações nas quais estão inseridas (Andrade, 2016). Ao tomar conhecimento dos artigos que discutem as relações de poder constituídas nas interações analisadas na obra em questão, o leitor poderá comparar-se a um mergulhador que, diante de um oceano de águas límpidas, avista um ouriço no fundo do mar, primeiro, de dentro de uma embarcação e, em seguida, com a cabeça imersa na água e equipado com snorkel. 0 poder, tal qual o ouriço, que antes apresentava um contorno tremido e difuso, passa a revelar um formato definido e detalhado. Categorias de percepção e orientação de condutas naturalizadas pelos indivíduos, antes descritas a partir de uma visão ética, i.e., cunhadas via entendimentos do analista, passam a ser descritas a partir de uma perspectiva êmica, i.e., com base no que os próprios participantes tacitamente demonstram ser relevante no aqui e agora nas conversas.

No primeiro artigo da sessão, Do que não se fala: assuntos tabus e momentos delicados em consultas ginecológicas e obstétricas, as análises realizadas por Ana Ostermann e Débora Rejane da Rosa equivalem ao equipamento de snorkel que permite ao leitor enxergar os formatos que o poder assume nas 
relações interpessoais no contexto investigado. As autoras mostram partes de conversas em que termos (e.g., sexo, vagina) revelamse tabus ou assuntos (e.g., sexualidade, estilo de vida) são tomados pelos próprios participantes como potenciais motivos de julgamentos morais. Pausas, hesitações, alongamentos de sons, produção de fala em volume mais baixo, substituição de termos especializados por termos coloquiais ou vice-versa ou, ainda, omissão de certos termos estão entre as marcas apresentadas nas falas e que evidenciam a dificuldade dos participantes em lidar com tópicos "delicados" ou palavras "incômodas" nas consultas analisadas. 0 exercício de poder ou a sua ausência exibem formatos definidos em situações em que, por exemplo, um dos médicos investigados deixa passar a oportunidade de produzir certo termo especializado (vagina) para e pela paciente sendo atendida por ele que, por sua vez, demonstra dificuldade em produzi-lo. Deixar a paciente "rir sozinha" (Haakana, 2002, p. 207) e "repreendêla" no instante em que ela exibe dificuldade em abordar sua ausência de libido., como ocorre em uma das interações analisadas, também evidencia como a assimetria nas relações é coconstruída no turno a turno das conversas.

Nessa mesma linha argumentativa, Ana Ostermann e Renata Ruy, em As relações de poder nas consultas ginecológicas e obstétricas, discutem como as estruturas comunicacionais, ao lado da autoridade profissional e das estruturas sociopolíticas (Maynard, 1991, p. 455456) concorrem para "dar forma ao poder". 0 foco das análises, nesse artigo, concentra-se em partes de conversas em que se observa os médicos realizando perguntas para pacientes, cujas respostas eles já conhecem, e, em seguida, avaliando suas respostas em termos de acurácia ou adequação. As ações empreendidas pelos participantes por meio da fala-eminteração condizem com uma sequência interacional reconhecida pelo acrônimo IRA (iniciação - resposta - avaliação). Sequências IRA mostram-se uma prática corriqueira em contextos educacionais tradicionais em situações de testagem de conhecimento de alunos, o que, evidencia a relação assimétrica de poder entre quem tem o direito de perguntar e avaliar e quem tem a obrigação de responder (Garcez, 2006). Ao descreverem e analisarem, de modo inédito, ocorrências de sequências IRA em contexto de atendimento à saúde, Ana
Ostermann e Renata Ruy, não apenas fazem transparecer uma maneira por meio da qual os médicos exercem poder sobre as pacientes no aqui e agora da interação, mas também contribuem para alargar o escopo de práticas de poder reconhecidas como atinente ao modelo biomédico de atendimento à saúde, quais sejam: interrupções da fala de pacientes, controle, por parte dos profissionais de saúde, dos assuntos a serem tratados nos encontros, a distribuição desigual do direito de perguntar e da obrigação de responder, entre outras práticas descritas na literatura (e.g., Ainsworth-Vaughn, 1998; Hak, 1994).

De maneira recorrente, a (as)simetria nas relações provedor de saúde - paciente é discutida à luz do princípio de Integralidade (e.g., Ayres, 2004; Mattos, 2005). Conforme Ruben Mattos (2005, p. 45),

\begin{abstract}
Integralidade [é] uma marca de um modo de organizar o processo de trabalho [visto que] não é aceitável que os serviços de saúde estejam organizados exclusivamente para responder às doenças de uma população, embora eles devam responder a tais doenças. Os serviços devem estar organizados para realizar uma apreensão ampliada das necessidades da população ao (sic) qual atendem.
\end{abstract}

0 modo integral de organizar o processo de trabalho, ao qual se refere Mattos, reverbera o Programa Nacional de Humanização do SUS, contexto dos atendimentos investigados na obra em questão. Segundo esse programa, o atendimento integral à saúde prevê "tanto [...] o aumento da qualidade da assistência, quanto [...] uma nova ordem relacional pautada no reconhecimento de alteridades e no diálogo". (Deslandes, 2004, p. 8). Os artigos de Ana Ostermann e Joseane de Souza e de Ana Ostermann e Caroline Silva, que compõem a terceira parte do livro, mostram como se traduz "uma ordem relacional pautada no reconhecimento de alteridades e no diálogo."

No artigo As explicações feitas pelas pacientes para as causas de seus problemas de saúde: como os médicos lidam com isso, Ana Ostermann e Joseane de Souza investigam momentos em que pacientes oferecem explicações voluntárias sobre as causas de saúde e/ou sintomas que as levaram a buscar auxílio médico, fenômeno interacional conhecido como atribuições. As autoras demonstram que, ao contrário do que apontam outros estudos focados no fenômeno das atribuições, os médicos investigados consideram as hipó- 
teses de causa e efeito levantadas pelas pacientes para o seu atual estado de saúde. As atribuições são consideradas pelos médicos investigados na medida em que eles proveem respostas para as pacientes, sejam de natureza conformativa com as expectativas exibidas, sejam de natureza explicativa para o motivo pelo qual determinada relação de causa e efeito não se aplica. Ao agirem assim, segundo Ostermann e Souza, os médicos mostramse interacionalmente sensíveis no sentido de valorizar as contribuições das pacientes. Em outras palavras, os médicos mostram-se abertos às alteridades (na medida em que valorizam os saberes trazidos pelas pacientes) e ao diálogo. Nesse aspecto, as autoras ponderam que é por meio de práticas interacionais, como, por exemplo, prover respostas que mostram atenção aos saberes leigos de pacientes, que se pratica humanização em atendimentos de saúde.

Outra prática humanizadora em contexto de saúde é discutida por Ana Ostermann e Caroline R. da Silva no artigo $A$ formulação explicitando a compreensão mútua entre médico $e$ paciente: uma forma de humanizar os atendimentos. Ao analisarem as conversas em foco no artigo, as autoras perceberam que há momentos em que, tanto os médicos, quanto as pacientes oferecem ao interlocutor um entendimento candidato do que foi dito nos turnos de fala anteriores. Essa prática interacional é conhecida na literatura da AC como formulação. Conforme explicam Ana Ostermann e Caroline R. da Silva, com base em John Heritage e Rod Watson (1979), ao formular uma parte da conversa de modo a oferecer um entendimento candidato sobre o que foi dito anteriormente, o próximo falante fica interacionalmente restrito a confirmar ou desconfirmar a interpretação oferecida. Dessa maneira, os participantes afinam a compreensão mútua de modo a sanar possíveis malentendidos.

A ocorrência da prática de formulação nas consultas analisadas, ponderam as autoras, concorre para descrição dos atendimentos como colaborativos, em contraposição a atendimentos que se parecem mais com interrogatórios, conforme estudos revisados no artigo (e.g., Hak e De Boer, 1996). Por um lado, os médicos, ao formularem as falas das pacientes, prestam um serviço de organização das informações trazidas à tona na interação por elas que, muitas vezes, "podem soar 'desordenadas e não claramente relacionadas entre si" (p. 107). Além disso, uma vez que a compreensão mútua é alcançada, os médicos, em determinadas circunstâncias, têm a oportunidade de esclarecer questões de saúde não compreendidas pelas pacientes e, assim, fazer um trabalho de "letramento" sobre aspectos relevantes à condição de saúde das próprias consultantes. Por outro lado, o fato de as pacientes mostrarem-se "à vontade" para formular as falas dos médicos, além de evidenciar uma faceta acolhedora dos atendimentos, resulta em maiores chances de elas saírem das consultas dotadas de informações melhor compreendidas o que, em última instância, propende a promover a adesão aos tratamentos prescritos.

Ambos os artigos que compõem parte do livro dedicada a tratar de humanização em saúde, enfim, revelam como o atendimento (não) humanizado está diretamente relacionado às práticas interacionais constituintes das interações locais. Destarte, pode-se ver como análises de ordem micro (i.e., da fala-eminteração) abastecem de maneira persuasiva discussões de ordem macro como as relacionadas, por exemplo, com poder, humanização, gênero e sexualidade; esses dois últimos tópicos tratados na última sessão analítica da coletânea.

Em Gênero e sexualidade no consultório ginecológico: pressupostos identitários jamais questionados, de Ana Ostermann e Aline Jaeger, e Tensionando identidades de gênero e sexualidade na fala-em-interação: o colapso discursivo da masculinidade homogênea, de Mariléia Sell e Ana Ostermann, gênero e sexualidade são entendidos como identidades coconstruídas de forma situada a cada interação social. Assim, identidades de gênero e sexualidade, ao contrário de fixas, constituem-se por meio de (re)negociações feitas pelos participantes na e pela fala-em-interação a cada novo evento social. Com base nesse pressuposto epistemológico, Ana Ostermann e Aline Jaeger, analisam consultas em que se percebem os médicos operando dentro de uma lógica social heteronormativa ao tratar pacientes em consultórios de ginecologia. Tal lógica emerge, por exemplo, em momentos em que os médicos questionam as pacientes sobre os métodos contraceptivos adotados por elas. Conforme discutem Ana Ostermann e Aline 
Jaeger, o fato de perguntas tais como "tá te cuidando direitinho?", "iniciou algum anticoncepcional?" ou "tu tá usando algum método?" constituírem uma práxis rotineira nas consultas concorre "para a naturalização da heterossexualidade como princípio organizador e normatizador da sociedade como um todo" (p. 130). Ao agirem assim, alegam as autoras, os médicos retroalimentam a concepção binária de gênero, em que apenas as identidades pareadas homem-mulher são ratificadas. Paralelamente a isso, a prática sexual heteroafetiva como comportamento social adequado da população é reificada de modo contumaz.

Outras duas questões são discutidas pelas autoras no que concerne à ocorrência do tipo de pergunta supracitado de modo rotineiro no contexto estudado. A primeira delas remonta ao fato de que os médicos, em geral, fazem as perguntas utilizando a segunda pessoa do singular. Assim, os médicos colaboram para a reafirmação da mulher como única responsável pelo controle da prole e, consequentemente, reiteram o homem como isento de compromisso nesse sentido. A segunda questão remete ao foco de maior preocupação emergente nas consultas analisadas, qual seja, a prevenção de gravidez indesejada. Conforme salientado no artigo, médicos e pacientes compartilham o entendimento de que "utilizar um método contraceptivo" para "evitar gravidez" equivale a "tomar pílula anticoncepcional". Nesse aspecto, o uso desse método é persuasivamente recomendado sem que seus possíveis efeitos colaterais para a saúde das pacientes sejam discutidos. Doenças sexualmente transmissíveis também não são topicalizadas, o que gera consequências práticas para a saúde das mulheres atendidas.

No último capítulo analítico da obra, Mariléia Sell e Ana Ostermann debruçam-se sobre interações entre candidatos à procedimento de vasectomia e a psicóloga que atende no mesmo posto de saúde onde os dados das pesquisas dos capítulos anteriores foram coletados. Em razão do procedimento de vasectomia ser oferecido gratuitamente pelo SUS, os candidatos veem-se obrigados a passar por uma consulta de psicologia para comprovarem sua "sanidade mental" e, assim, obterem acesso ao procedimento.

O principal fator de agregação deste capítulo para a obra, é a incorporação da Análise de
Categoria de Pertença (ACP) como ferramenta analítica em conjunto com a AC na inspeção e discussão de dados. Como explicam Sell e Ostermann (p. 136), com base em Harvey Sacks (1992), “a ACP não se propõe a recorrer a categorias prontas [.... ou] tampouco apela para categorias de senso-comum" para interpretar dados, mas debruça-se sobre as categorias que os próprios participantes tornam relevante na interação. Ao invocar determinada categoria, em detrimento de outras tantas possíveis para se auto descrever ou descrever outra pessoa, o falante revela como, para os efeitos práticos da interação local, enxerga quem está sendo descrito. A escolha e explicitação de atributos (e.g., aquela morena vs. aquela mulher sentada na ponta da mesa) ou de ações (e.g., o namorador vs. o aluno da faculdade tal) denotam a identidade emergente na fala a partir "[d]o que é ligado às pessoas [sendo descritas] e aos seus comportamentos". Sell e Ostermann utilizam-se dos princípios epistemológicos da ACP e da AC para analisar as ações sequenciais de categorizar e discutir como traços identitários masculinos tomados de forma homogênea no sensocomum, normalmente, associados à virilidade e destemor tornam-se passíveis de serem "tencionados e desestabilizados" (p. 146) e, portanto, necessitando serem reiteradamente provados na interação.

Como se pode apurar a partir das análises propostas no livro organizado por Ostermann e Meneghel, não existem relações (as)simétricas, (des)humanizadas ou (de)generificadas fora do discurso ou, mais especificamente, fora da interação com o(s) outro(s). Considerando que todos os dados que servem às análises apresentadas na obra foram gerados no mesmo posto de saúde, há, em certa medida, um cruzamento entre os temas abordados no livro e os profissionais sujeitos de pesquisa. Esse cruzamento é significativo na medida em que se percebe que os mesmos médicos que adotam práticas humanizadoras nos atendimentos nem sempre estão atentos a questões relevantes como, por exemplo, a naturalização da heteronormatividade de "forma insidiosa em situações cotidianas de atendimento à saúde da mulher" ( $p$. 130) ou a dificuldade das pacientes em abordar temas relacionados à sexualidade ou estilo de vida. Longe de categorizar os atendimentos visitados dicotomicamente (i.e., bom/ruim, humanizado/desumanizado), as 
autoras mostram que, interacionalmente e, portanto, socialmente falando, os profissionais de saúde operam em um continuum. Por essa razão, há sempre espaço para trabalhar a sensibilização interacional desses profissionais de modo a promover a melhora das relações interpessoais em contextos de atendimento em saúde. No fechamento do livro, Ostermann e Meneghel discorrem, não de maneira prescritiva mas de forma reflexiva, sobre como estudos de fala-em-interação podem informar sobre recursos interacionais capazes de agregar valor humanizador à relação profissional de saúde-usuário. Uma obra verdadeiramente reveladora e útil.

\section{Referências}

Ainsworth-Vaughn, Nancy (1998). Claiming power in doctor-patient talk. Oxford: Oxford University Press. http://dx.doi.org/10.2307/2654127

Andrade, Daniela. N. P. (2016). Recomendações e prescrições para cuidados de saúde no pós-alta: a investigação de um programa educativo a pacientes cardiopatas sob uma perspectiva interacional. Tese de doutorado inédita, Universidade do Vale do Rio dos Sinos.

Ayres, José R. C. M. (2004). O cuidado, os modos de ser (do) humano e as práticas de saúde. Sociedade e Saúde, 13(3), 16-29. http://dx.doi.org/10.1590/s010412902004000300003

Bourdieu, Pierre (1991). Language and symbolic power. Cambridge: Polity Press. http://dx.doi.org/10.1093/sf/71.1.242

Deslandes, Suely (2004). Análise do discurso oficial sobre a humanização da assistência hospitalar. Ciência \& Saúde Coletiva, 9(1), 7-14. http: //dx.doi.org/10.1590/s141381232004000100002

Garcez, Pedro M. (2006). A organização da fala-eminteração na sala de aula: controle social, reprodução de conhecimento, construção conjunta de conhecimento. Calidoscópio, 4(1), 66-80.

Haakana, Markku (2002). Laughter in medical interaction: from quantification to analysis, and back. Journal of Sociolinguistics, 6(2), 207-235. http://dx.doi.org/10.1111/1467-9481.00185

Hak, Tony (1994). The interaction form of professional dominance. Sociology of Health and Illness, 16(4), 469-488. http://dx.doi.org/10.1111/14679566.ep11347541

Hak, Tony \& De Boer, Frank (1996). Formulations in first encounters. Journal of Pragmatics, 25, 8399. http://dx.doi.org/10.1016/03782166(94)00076-7

Heritage, John (2004). Conversation Analysis and institutional talk: analyzing data. In David Silverman (Org.), Qualitative research: theory, method and practice (pp. 103-147). London: Sage publications.

Heritage, John \& Watson, Rod (1979). Formulation as a conversation objects. In George Psathas (Ed.). Everyday Language (pp. 123-162). New York: Irvington Press.

Heritage, John \& Watson, Rod (1980). Aspects of the properties of formulations in natural conversations: some instances analysed. Semiotics, 30, 245-262.

http://dx.doi.org/10.1515/semi.1980.30.3-4.245

Hutchby, lan \& Wooffitt, Robin (1998). Conversation analysis: principles, practices and applications. Cambridge: Polity Press.

Mattos, Ruben (2005). Os sentidos da integralidade: algumas reflexões acerca de valores que merecem ser defendidos. In Roseny Pinheiro.\& Ruben Mattos (Orgs.), Os sentidos da integralidade na atenção e no cuidado em saúde (pp. 43-68). Rio de Janeiro: Cepesc/IMS/Uerj/Abrasco.

Maynard, Douglas W (1991). Interaction and asymmetry in clinical discourse. The American Journal of Sociology, 97(2), 448-495. http://dx.doi.org/10.1086/229785

Oliveira, Maria do Carmo L. De (2013). Linguística Aplicada a contextos empresariais: uma entrevista com Maria do Carmo Leite de Oliveira. ReVEL, , 11(21).

http://www.revel.inf.br/files/98fc048cb3e41395 7a93a6bf71d3232a.pdf

Ostermann, Ana Cristina \& Meneghel, Stela Nazareth (Orgs.) (2012). Humanização, Gênero, Poder: contribuições dos estudos de fala-eminteração para a atenção à saúde. Campinas: Mercado de Letras; Rio de Janeiro: Fiocruz.

Sacks, Harvey (1992). Lectures on conversation. Oxford: Blackwell, v. 1 e v. 2.

Schegloff, Emanuel (2007). A Sequence organization in interaction: a primer in conversation analysis. Cambridge: Cambridge University Press. 


\section{Daniela Negraes Pinheiro ANDRade}

Possui doutorado em Linguística Aplicada pela Universidade do Vale do Rio dos Sinos. Realizou doutorado sanduíche na University of California-Los Angeles (UCLA). É membra participante do grupo de pesquisa Fala-em-interação (FEI), coordenado pela Profa. Dra. Ana Cristina Ostermann. É membra participante também da International Gender and Language Association (IGALA) e da International Association of Forensic Linguistics.

DIRECCIÓN DE CONTACTO

danielanegraes23@gmail.com

\section{FORMATO DE CITACIÓN}

Andrade, Daniela Negraes Pinheiro (2016). Resenha de Ostermann e Meneghel (Orgs.) (2012)

Humanização, Gênero, Poder: contribuições dos estudos de fala-em-interação para a atenção à saúde. Quaderns de Psicologia, 18(1), 145-151. http://dx.doi.org/10.5565/rev/qpsicologia.1345 